\title{
Mielolipoma extraadrenal perirenal: aportación de un caso y revisión de la literatura
}

\author{
Pascual García X, Bujons Tur A, Rodríguez Faba O, Gómez Ruiz JJ, Palou Redorta J, \\ Villavicencio Mavrich $\mathrm{H}$.
}

Unidad de Uro-Oncología. Servicio de Urología. Fundació Puigvert. Barcelona.

Actas Urol Esp. 2007;31(8):932-934

\section{RESUMEN}

MIELOLIPOMA EXTRAADRENAL PERIRENAL: APORTACIÓN DE UN CASO Y REVISIÓN DE LA LITERATURA

El mielolipoma extra-adrenal es raro, son tumores benignos compuestos de material hematopoyetico y tejido graso. Pero, estos tumores pueden presentarse con hemorragia, aunque suelen ser asintomático. Generalmente se descubren de forma casual con el estudio de otras patologías. Presentamos el caso clínico de un paciente que a raíz de estudio de dolor lumbar se diagnostica de mielolipoma pararrenal.

Palabras clave: Mielolipoma. Tumor benigno. Extraadrenal

\section{ABSTRACT}

REPORT OF A CASE AND REVIEW OF THE LITERATURE

Extra-adrenal myelolipomas are rare bening tumours that are componed of mature fat cells and myeloid elements. These lesions are usually asyntomatic and often found incidentally on radiographic studies. We report a case of extra-adrenal perirenal myelolipoma.

Keywords: Myelolipoma. Bening tomour. Extra-adrenal.

$\mathrm{E}^{1}$ mielolipoma es un tumor infrecuente constituido por elementos hematopoyéticos en diferentes estadios madurativos y sin alteraciones histológicas, combinados en diferentes proporciones con tejido adiposo maduro ${ }^{1}$.

La localización más frecuente es la adrenal encontrándose hasta en el $0.4 \%$ de las autop$\operatorname{sias}^{2}$. La forma extraadrenal más frecuente es abdominal, sobre todo en la región presacra que representa la mitad de los casos. También se han comunicado casos en el estómago ${ }^{3}$, hígado ${ }^{4}$, nódulos linfáticos mediastino y cráneo ${ }^{5}$.

La fosa renal representa una localización extremadamente infrecuente en el caso de mielolipomas extra-adrenales y son muy pocos los casos descritos hasta ahora.
Aportamos un nuevo caso de mielolipoma extraadrenal de localización perirenal revisando su etiología, diagnóstico diferencial y el tratamiento.

\section{CASO CLÍNICO}

Presentamos el caso clínico de un paciente varón de 60 años de edad, con antecedentes personales de HTA, diabetes mellitus e hipercolesterolemia, diagnosticado de nódulo pulmonar en lóbulo superior derecho de $2,5 \mathrm{~cm}$, con fibrobroncoscopia y PAAF negativos y que debutó en mayo de 1998 con nefropatía diabética iniciando hemodiálisis en septiembre de 1999.

El paciente acudió a nuestro servicio de urgencias en agosto del 2004 por un dolor cólico izquierdo de un mes de evolución, se le realizó 
historia clínica con exploración física sin anormalidades y tacto rectal con próstata grado II- III adenomatosa bien delimitada.

Se realizaron exploraciones complementarias con analítica de sangre con valores dentro de la normalidad y en la radiografia de abdomen ausencia de calcificaciones pélvicas sin imágenes compatibles con litiasis renal, en la ecografía renovesical se informó de ectasia uréteropielocalicial izquierda terminal.

Se decidió la realización de una resonancia magnética en septiembre del 2004 que informó de masa de unos $4,5 \mathrm{~cm}$. adyacente al músculo psoas derecho con mínimo contacto con el margen medial del polo renal inferior y captación no homogénea compatible con proceso tumoral.

Se decidió control de esta lesión con CT que se realizó en enero del 2005 donde se informó de persistencia de masa hipodensa con mediciones en el rango de la grasa localizada entre el polo inferior de riñón derecho y músculo psoas del mismo lado de 42 x $37 \mathrm{~mm}$ compatible con angiomiolipoma sin poder descartar liposarcoma de bajo grado. Se objetivó así mismo otra lesión hipodensa de contenido graso entre la vena cava inferior y psoas derecho compatible con angiomiolipoma o adenopatía de contenido graso de 42 $\mathrm{mm}$. El riñón y vía urinaria izquierdos en este TAC de control fueron normales (Fig. 1).

Se decidió la realización de cirugía con nefrectomía radical derecha laparoscópica y exéresis de masa de consistencia grasa en situación paracava. $\mathrm{El}$ paciente presentó un postoperatorio sin incidencias.

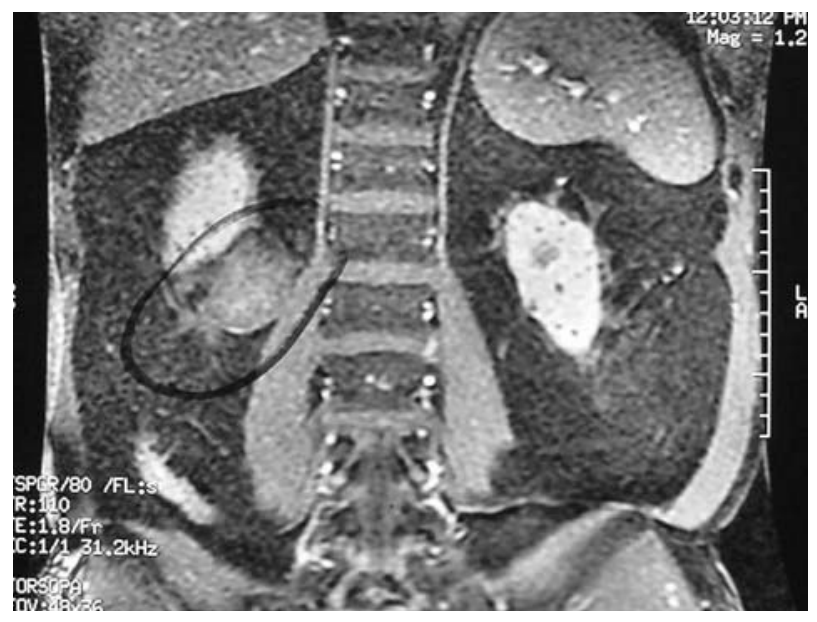

FIGURA 1
La anatomía patológica de la pieza fue de tumoración glandular formada por tejido adiposo maduro, tejido fibromuscular y acumulo de tejido mieloide que no infiltra estructuras vecinas y con vena renal libre de tumor. Atrofia túbulointersticial, inflamación crónica y esclerosis de glomérulos. Mielolipoma paraureteral derecho.

\section{DISCUSIÓN}

La localización adrenal del mielolipoma es la más frecuente constituyendo un tumor hormonalmente silente ${ }^{6}$. La forma extra-adrenal más habitual es la abdominal con preferencia por la región presacra, donde se localizan el 50\% de los mielolipomas extra-adrenales. Se han descrito casos de localización gástrica ${ }^{3}$, hepática ${ }^{4}$, en nódulos linfáticos, mediastino, cráneo ${ }^{5}$ y esplenico ${ }^{13}$.

El origen de este tumor no responde a una teoría clara, ha sido atribuido a una metaplasia inicial de células adrenales mesenquimales en grupos de células madre hematopoyéticas durante el esbozo de la glándula adrenal en el desarrollo embrionario ${ }^{7}$. También se apunta su origen a partir de restos corticales adrenales, la presencia de linfocitos en la corteza adrenal y su similitud con células madre hematopoyéticas, soportan la evidencia de esta teoría.

Durante el desarrollo embrionario existen focos de hematopoyesis extramedular ubicados en el peritoneo que regresan con la aparición de otros centros hematopoyéticos maduros al avanzar el desarrollo embrionario. La aparición fuera de la embriogénesis de hematopoyesis extramedular se ha observado en muchas condiciones patológicas como sepsis y estados infecciosos, por tanto un mecanismo similar a la hematopoyesis extramedular en situaciones patológicas podría explicar el origen embrionario del mielolipoma ${ }^{8}$.

Clínicamente cursan mayoritariamente de forma asintomática, aunque el efecto masa puede generar dolor abdominal, pérdida de peso, masa palpable, complicaciones gastrointestinales $\mathrm{y}$ dolor lumbar ${ }^{5}$, en nuestro caso las manifestaciones clínicas del paciente comenzaron con dolor lumbar. La diferencia clínica con las masas formadoras de hematopoyesis extramedular es que estas últimas se asocian a desórdenes mieloproliferativos, anemia hemolítica y trastornos esqueléticos severos ${ }^{9}$. 
Otros estudios experimentales y clínicos sugieren la existencia de una disfunción endocrina en la etiología, ya que inyectando extractos de pituitaria subcutánea en ratas, se veía inducida la mielopoyesis.

El Sindrome de Cushing, Addison, hiperplasia adrenal y administración exógena y crónica de esteroides se han asociado con el desarrollo de mielolipomas ${ }^{10}$.

Existen 4 patrones clínico- patológicos según localización y clínica para la definición de los mielolipomas ${ }^{1}$ :

a) adrenal aislada,

b) adrenal con hemorragia,

c) adrenal con asociación a patología adrenal y

d) extraadrenal.

La ecografia evidencia heterogenicidad debida a su arquitectura no uniforme, y la TAC y RMN se muestran como pruebas eficaces para le diagnóstico describiéndose en la TAC un tumor redondeado con una fina cápsula compuesto principalmente por tejido graso con áreas de densidad atenuada $^{12}$, aunque en muchas ocasiones se detecta de forma casual.

La PAAF con tinción de Romanowsky para reconocer elementos hematopoyéticos ha mostrado utilidad relativa ${ }^{11}$.

El examen anatomo-patológico revela la presencia de tejido adiposo maduro y células hematopoyéticas, variando en proporción en relación con el área, pudiéndose encontrar células de las 3 líneas (mieloide, eritroide y megacariocítica), también pueden estar presentes agregados linfocitarios y células plasmáticas. Frecuentemente puede asociar áreas de calcificación y osificación ${ }^{5}$.

El diagnóstico diferencial debe realizarse con otros tumores hematopoyéticos extramedulares, aunque estos habitualmente se asocian a anemia severa y cuadros mieloproliferativos preferentemente esplenomegalia y hepatomegália ${ }^{9}$.

La mayoría de autores coinciden en que aunque se trata de tumores con historia natural desconocida, el hecho de que puedan crecer localmente y producir síntomas, y la necesidad de realizar diagnóstico diferencial con tumores malignos retroperitoneales, especialmente liposarcomas ,les hace tributarios de cirugía exerética por vía abierta o laparoscópica.

\section{CONCLUSIONES}

El mielolipoma extraadernal perirrenal, es una rara entidad dentro de la localización extraadrenal del mielolipoma, la patogénesis de los mielolipomas es desconocida, la más aceptada es la capacidad metaplásica de las células estromales indiferenciadas presentes en la corteza adrenal, que respondería a diferentes estímulos: necrosis, infección o stress diferenciándose hacía adipositos y elementos hematopoyéticos. Clínicamente cursa de forma asintomática aunque el crecimiento puede provocar síntomas de compresión local. En el diagnóstico la TAC ha mostrado utilidad clínica. Se debe hacer diagnóstico diferencial con tumores retroperitoneales malignos especialmente con liposarcomas y el tratamiento debe ser quirúrgico vía abierta o laparoscópica.

\section{REFERENCIAS}

1. Torres Gómez FJ, Torres Olivera FJ, García A. Mielolipoma extraadrenal. Localización presacra: Un nuevo caso. Oncología, 2005; 28(6) 304-307.

2. Asunción CM, Loh WP. Myelolipoma of the adrenal gland. J Indiana State Med Assoc. 1965;58:38-43.

3. Le Bodic MF, Mussini-Montpellier J, Magois JY, Lepere J. Myelolipoma of the stomach. Arch. Anat. Pathol (Paris). 1974;22(2):119-122.

4. Gonzalez EM, Gonzalez JBS, Martinez JB, Santoyo JS, Sanz RG, Castrijon JV, et al. Hepatic myelolipoma: A new case and review of the literature. Hepatogastroenterology. 1991;38(1):60-63.

5. Sneiders A, Zhang G, Gordon BE. Extra-Adrenal perirenal myelolipoma. J. Urol. 1993;150(5 Pt 1):1496-1497.

6. d'Addessi A, Racioppi M, Fanasca A, Zannoni GF, Alcini E. A rare case of perirenal myelolipoma. Scand J Urol Nephrol. 1997;31(6):579-581.

7. Boudreaux D, Waisman J, Skinner DG, Low R. Giant adrenal myelolipoma and testicular interstitial cell tumor in a man with congenital 21hydroxylase deficiency. Am.J Surg Pathol. 1979;3(2):109-123.

8. Amin MB, Tickoo SK, Schultz D. Myelolipoma of the renal sinus. An unusual site for a rare extra- adrenal lesion. Arch pathol lab Med. 1999;123(7):631-634.

9. Chen KT, Felix EL, Flam MS. Extraadrenal myelolipoma. Am J Clin Pathol. 1982;78(3):386-389.

10. Wagner JR, Kleiner DE, McClellan MW, Linehan WM. Perirenal myelolipoma. Urology. 1997;49(1):128-130.

11. Bryan JA, Sykes CH, Garvin DF. Fine needle aspiration diagnosis of a mesenteric myelolipoma: A case report. Acta Cytol. 1996;40(3):592594.

12. Sutker B, Balthazar EJ, Fazzini E. Presacral myelolipoma: CT findings. J. Comput. Assist. Tomogr. 1985;9(6):1128-1130.

13. López Lobato M, Selas Pérez A, Devesa Múgica M, Castro Iglesias AM, Troncoso Suárez A, Puig Saez M.. Mielolipoma Suprarenal. Actas Urológicas Españolas. 1993;(17):592-594.

Correspondencia autor: Dr. D. Xavier Pascual García Fundación Puigvert. Cartagena, 340-350 - 08025 Barcelona Tel.: 934169700

E-mail autor: pascualxavier2@hotmail.com

Información artículo: Nota clínica

Trabajo recibido: enero 2006

Trabajo aceptado: abril 2006 